\title{
Absence of lexical and orthographic effects in a same-different task
}

\author{
K. I. FORSTER \\ Monash University, Clayton, Victoria 3168, Australia
}

\begin{abstract}
Two experiments are reported that investigate whether the lexical and orthographic effects typically found in a simultaneous matching task are due to the facilitating effect of linguistic context on letter identification. The first experiment used a delayed matching task (2-sec SOA), with serial incremental display of the letters of the second stimulus (e.g., B, BR, BRA, BRAI, BRAIN). Lexical and orthographic effects were clearly demonstrated when the letters of the second stimulus were displayed rapidly $(40 \mathrm{msec} / \mathrm{letter})$, but these effects were absent at a slower speed $(400 \mathrm{msec} / \mathrm{let}$ ter). The same results were obtained in a second experiment, in which the letters of both stimuli were synchronously presented at either the fast rate or the slow rate. These results were interpreted in terms of a multilevel race model that assumes no interaction between levels of processing and attributes the effects to differing degrees of decision-processing lag.
\end{abstract}

In a simultaneous matching task, two types of familiarity effects can be observed for "same" items (Barron \& Pittenger, 1974; Chambers \& Forster, 1975). First, there is a purely orthographic effect, as shown by the fact that orthographically legal nonword pairs (e.g., GRAIM/ GRAIM) are matched faster than illegal nonword pairs (e.g., RKLNI/RKLNI). Second, there is an effect of lexical status, as shown by the fact that word pairs are matched faster than legal nonword pairs, even when the nonwords are composed of more frequently occurring letter sequences than the words (Chambers \& Forster, 1975, Experiment 2).

It is often supposed that these results merely confirm the already demonstrated effects of linguistic context on letter identification. The orthographic effect results from the fact that distributional constraints reduce the number of possible alternatives at any particular letter position. If the letter identification system is biased so that orthographically legal alternatives are evaluated before illegal alternatives, then legal sequences will be identified faster than illegal sequences. If the identification system is further biased so that alternatives actually occurring in the language are given priority over merely possible alternatives, then it follows that words will be identified faster than legal nonwords. Thus, in a four-letter display, if the first three letters have been identified as BOA, then we would expect $R$ and $T$ to be the first possibilities considered for the final letter, since only these letters form words. If neither of these alter-

This article is based on a paper delivered at the Sixth Australian Experimental Psychology Conference, Australian National University, May 1979. The research was supported by a grant from the Australian Research Grants Committee. Requests for reprints should be addressed to K. I. Forster, Department of Psychology, Monash University, Clayton, Victoria 3168, Australia. natives produces an acceptable match with the stimulus, then the next set to be considered would be the orthographically legal completions of the sequence (D, F, L, etc.), and only if these all fail would the remaining letters be considered. Such a theory has also been proposed as an explanation of the word-superiority effects observed in the forced-choice tachistoscopic recognition experiments originated by Reicher (1969) and Wheeler (1970) The fact that these effects are eliminated when the subject has advance information about the alternatives and the position in which they occur (Thompson \& Massaro, 1973) can be taken as support for this contextual theory.

The purpose of this paper is to examine an alternative explanation of the same-different matching results that makes no assumptions about contextual effects at all. This theory is a multilevel race model, and it is described in Chambers and Forster (1975). The essential feature of this theory is the assumption that the two stimuli are capable of being compared at any one of three entirely separate and independent levels of processing: the letter level, the letter cluster level, and the lexical level. Thus two words could be compared as sequences of separate letters or as sequences of letter clusters (or perhaps syllables), or they could be compared as words. Whichever level of comparison reaches a conclusion first controls the eventual decision and, hence, decision time.

No strong assumptions are made about the speed with which the perceptual units at each level are identified. However, it is assumed that the identification times are quite short relative to the comparison and decision times. This means that the letter level is unlikely to be the fastest method of comparison for "same" items, since the number of comparisons will be equal to the number of letters in each stimulus and the decision processor has to evaluate the outcomes of all these comparisons; 
however, at the word level, only one comparison is required. Hence, even if it took longer to identify the stimulus as a word than as a sequence of letters, the smaller number of comparisons and decisions gives an advantage to the lexical level of processing. The lexical level will also be faster than the letter cluster level, since for nearly all words, more than one letter cluster will be involved. However, since there will usually be fewer clusters than individual letters, the letter cluster level is still faster than the letter level.

This theory predicts both of the familiarity effects, since only words can be processed at the fastest level (the lexical level) and only legal sequences can be processed at the letter cluster level. However, the situation changes completely for "different" items. For these items, processing time at the lexical level remains constant, since the lexical identification of each stimulus is still required to determine that the stimuli are different. However, at the lower levels, not all elements need to be compared before a decision is reached (assuming that a serial comparison strategy is used). For example, if all letters differ, as in CHART/STEAL, only one letter pair needs to be compared before a difference is detected, hence processing at the letter level is much faster for "different" items. Thus, as might be expected, when all letters differ, there are no differences at all between words, legal nonwords, and illegal nonwords (Chambers \& Forster, 1975), suggesting that letters can in fact be identified at least as rapidly as letter clusters or words.

So far, there is nothing to distinguish this theory from the contextual theory. Both theories predict familiarity effects for "same" items, and it is also possible to extend the contextual theory to cover the results for "different" items. For example, any effects of context would be limited to letters occurring relatively late in the sequence, and hence contextual effects should be weak if the difference occurs in the early letters. However, if the difference occurs in the final letters, contextual effects should be stronger. This is precisely what was found by Chambers and Forster (1975).

But there is one situation in which the two theories make different predictions. Suppose that the method of presentation is changed in the following way. Instead of presenting both stimuli simultaneously, one above the other, the first stimulus is presented alone, and the second stimulus is then presented beneath the first, one letter at a time from left-to-right without erasure of the preceding letter. The subject is free to respond at any time, but he obviously cannot correctly respond "same" until the two displays are complete. According to the context theory, the matching time for "same" items will still be a function of how rapidly the last letter can be identified, and this should still be influenced by the context provided by the previous letters. However, the race model makes a different prediction. If the second stimulus is presented slowly enough, decision making on the basis of letter-level comparisons should be able to keep pace with the input, so that when the last letter of the second stimulus is presented, only one comparison needs to be made to produce a clear decision. This means that there is no advantage accruing to the higher levels of processing, and if a single pair of letters can be matched as rapidly as a pair of letter clusters or words, then no familiarity effects will be observed.

However, if the letters of the second stimulus are presented at a faster rate, then decision making at the lower levels will tend to lag behind, and the familiarity effects observed for the simultaneous presentation condition should reappear. The following experiments were designed to test this hypothesis.

\section{EXPERIMENT 1}

The procedure used in this experiment can be termed a delayed same-different task, with serial incremental display of the letters of the second stimulus. The task is delayed, since there is a $2-\sec$ onset asynchrony between the two stimuli (rather than both being presented together). The method of display of the second stimulus is serial, since it is presented one letter at a time, and it is incremental, since the preceding letters are not erased as each new letter is presented. Thus, the display changes in the following way:

\section{CHART CHART CHART CHART CHART C $\quad \mathrm{CH}$ CHA CHAR CHART}

Two presentation speeds were used for the second stimulus. The slow rate $(400 \mathrm{msec} / \mathrm{letter})$ was intended to allow all processing for a given letter to be completed before the next letter was presented. The fast speed ( $40 \mathrm{msec} / \mathrm{letter})$ was intended to prevent this, and thus to produce effects similar to those produced by simultaneous presentation of all letters.

Three types of items were used: words, legal nonwords, and illegal nonwords. If the assumptions of the race model are correct, then the normal familiarity effects for "same" items should be observed only for the fast presentation condition. The contextual theory, however, predicts that the familiarity effects should be unaffected by speed of presentation.

\section{Method}

Construction of materials. All items contained five letters. The stimuli were based as far as possible on the materials used in Chambers and Forster (1975). The words were chosen so that there was always another word with the same first four letters [e.g., SLEEP (SLEET), GUESS (GUEST)]. Words not meeting this condition (e.g., WHEAT) would enable the subject to infer that the correct response must be "same" before all letters in the second stimulus had been presented. For example, in the display WHEAT/WHEA-, there is no word other than WHEAT that can be presented, and since words were always paired with words, the correct response would have to be "same." Some adaptation of the Chambers and Forster items was necessary to 


\section{FORSTER}

meet this condition. However, the legal nonwords and illegal nonwords were exactly the same as in the Chambers and Forster study. The legal nonwords in this study were constructed so that the mean bigram and trigram frequencies were typical of actual English words. The illegal nonwords were random combinations of letters taken from the original word pool.

Typical examples of the items were as follows: wordsSHORT, SPEND, SCORE, NOISE, STEEL, GREED, BLOOM; legal nonwords-BLOUT, SONTH, GRAIM, MINCH, STARP, HILCH, DRASH; illegal nonwords-ETRNO, RKLNI, HLSAE, FODTN, ETSPT, GNEGO, LWEOR.

Design. The two presentation speeds were combined factorially with the three types of items. For the "same" items, the materials were counterbalanced on the presentation factor, so that each item was presented at both speeds. This necessitated having two groups of subjects. An item presented at the slow speed for one group was presented at the fast speed for the other, and vice versa. No item was ever seen more than once by any subject. For each group, there was a different set of 15 "same" items in each of the six conditions, making a total of 30 items in each condition over both groups.

The "different" items consisted of 10 items in each of the six conditions in which the difference occurred in the fifth letter, together with a further sample of 5 items in each condition in which the difference occurred in either the first or the third letter. Thus the overall number of "same" and "different" items was equated. The more critical comparison, however, is the balance of "same" and "different" just prior to the presentation of the last letter of the second stimulus. Here the ratio was 15:10 in favor of "same."

Procedure. The items were presented as uppercase letter sequences using a 7 by 9 dot matrix video display under computer control. The first stimulus sequence was presented in the center of the viewing screen and remained in view until the trial was completed. After $2 \mathrm{sec}$ had elapsed, the first letter of the second stimulus sequence was presented immediately beneath the first letter of the first sequence. The remaining four letters of the second stimulus were then displayed successively at a rate of either $40 \mathrm{msec} / \mathrm{letter}$ or $400 \mathrm{msec} / \mathrm{letter}$. Each letter of this sequence also remained in view until the trial was completed.

Subjects were instructed to respond "different" as soon as they detected any difference between the two sequences. It was explained that the second sequence would always be the same length as the first, and hence if the first four letters were the same, they could respond "same" as soon as they detected that the fifth letters were also the same. Subjects responded to "same" items by pressing a button with the preferred hand and to "different" items by pressing a button with the nonpreferred hand.

The 180 experimental items were presented in a different semirandom order for each subject. The speed condition was not blocked; that is, the subject did not know whether the second sequence would be presented rapidly or slowly.

The instructions emphasized both speed and accuracy. At the completion of each trial, the subject was provided with feedback concerning both accuracy and speed.

Decision times were measured by a programmable clock with an accuracy of $1 \mathrm{msec}$. Timing of the response for "same" items always began when the last letter of the second stimulus was presented.

Subjects. A total of 30 volunteer undergraduate and graduate students served as subjects and were paid for participation in the experiment.

\section{Results}

Incorrect responses were discarded, and values exceeding cutoffs established 2 SDs above or below the mean for each subject were set equal to the cutoff value.
Since familiarity effects were not necessarily expected for the distractors, the analysis was restricted to the "same" items. The mean decision times for these items are shown in Table 1.

These means were analyzed in a 2 by 3 by 2 factorial analysis of variance; the factors were groups, item type (words, legal nonwords, and illegal nonwords), and presentation speed (fast vs. slow), and there were separate analyses for subject means and item means. In the subject analysis, "groups" refers to subject groups, and this was the only nonrepeated-measures factor. In the item analysis, "groups" refers to item groups (the random division of the items into two halves for the purpose of counterbalancing), and the only repeated-measures factor was presentation speed. The results of the two analyses were then combined using the min $F^{\prime}$ procedure described by Clark (1973).

As Table 1 shows, there was a substantial effect of presentation speed, with fastest performance at the slower speed. This effect was significant $\left[\min F^{\prime}(1,39)=\right.$ $113.1, \mathrm{p}<.001]$. Words were matched faster than legal nonwords (442 vs. $465 \mathrm{msec}$ ), which in turn were matched faster than illegal nonwords $(506 \mathrm{msec})$. This main effect was significant $\left[\min F^{\prime}(2,130)=17.81\right.$, $\mathrm{p}<.001]$, but it is clear that the familiarity effects for the fast speed ( 38 and $72 \mathrm{msec}$ ) were much greater than those for the slow speed $(7$ and $11 \mathrm{msec})$. This was a significant difference, as indicated by the significant interaction between item type and presentation speed $\left[\min \mathrm{F}^{\prime}(2,135)=14.13, \mathrm{p}<.001\right]$. The error rates followed the pattern of decision times throughout, but the only effect to reach significance was that of presentation speed [min $\left.F^{\prime}(1,76)=9.55, p<.001\right]$.

The one question not resolved by this analysis was whether there were any familiarity effects at the slow presentation speed. Pairwise comparisons showed that the obtained effects were far from reliable. The lexical effect of $7 \mathrm{msec}$ was not significant $\left[\min F^{\prime}(1,83)=.37\right.$, $p>.05$ (neither $F_{1}$ nor $F_{2}$ was significant)], whereas the same comparison at the fast speed was highly significant $(\mathrm{p}<.001)$. Similarly, the orthographic effect of $11 \mathrm{msec}$ was not significant $\left[\min \mathrm{F}^{\prime}(1,50)=.69, \mathrm{p}>.05\right.$ (neither $F_{1}$ nor $F_{2}$ was significant)], while the same effect was again highly significant at the fast speed $(p<.001)$. The post hoc combination of these two effects (words vs. illegal nonwords) produced a similar outcome $\left[\min F^{\prime}(1,54)=1.72, p>.05\right.$ (although in this case $F_{2}$ was significant, $\mathrm{p}<.05$, while $F_{1}$ was not)] . Evidently,

Table 1

Mean Decision Time (RT) in Milliseconds and Percent Error

Rates (PE) for "Same" Items in a Delayed Matching Task With Serial Incremental Display of the Second Stimulus (Experiment 1)

\begin{tabular}{|c|c|c|c|c|c|c|}
\hline \multirow{2}{*}{$\begin{array}{l}\text { Presenta- } \\
\text { tion Rate }\end{array}$} & \multicolumn{2}{|c|}{ Words } & \multicolumn{2}{|c|}{ Legal Nonwords } & \multicolumn{2}{|c|}{ Illegal Nonwords } \\
\hline & RT & $\mathrm{PE}$ & RT & $\mathrm{PE}$ & RT & $\mathrm{PE}$ \\
\hline $\begin{array}{l}\text { Fast } \\
\text { Slow }\end{array}$ & $\begin{array}{l}490 \\
394\end{array}$ & $\begin{array}{l}4.7 \\
2.0\end{array}$ & $\begin{array}{l}528 \\
401\end{array}$ & $\begin{array}{l}8.0 \\
2.0\end{array}$ & $\begin{array}{l}600 \\
412\end{array}$ & $\begin{array}{l}9.3 \\
5.3\end{array}$ \\
\hline
\end{tabular}


some subjects showed a trend in this direction and others did not.

\section{Discussion}

The results of this experiment demonstrate for the first time that it is possible in a matching task to eliminate the word-superiority effect for "same" items and to at least drastically reduce the orthographic effect. Thus, not only do the familiarity effects depend on whether the items are the same or different (Chambers \& Forster, 1975), but they also depend on the method of presentation. Both of these results are predictable from a multilevel race model that assumes independent levels of processing and explains effects in terms of differing degrees of decision-processing lag.

Whether the familiarity effects have been totally eliminated at the slow speed or merely attenuated is, of course, difficult to establish. To some extent, this may be an irrelevant question, since the race model is not actually committed to a total elimination of the effects. This would be the case only if for every subject and for every item, decision processing at the letter level could always keep pace with the input. It is quite likely that some subjects occasionally would be unable to sustain the required rate of one decision every $400 \mathrm{msec}$, either because they make decisions very slowly or because of lapses of attention. Any tendency in this direction would tend to produce a limited effect. The statistical analysis of the "same" responses provides some support for this proposal, since at the slow speed, the word/illegal nonword difference was significant in the item analysis but not in the subject analysis. This is a most unusual result, since usually it is the subject analysis that produces the strongest trends in language processing experiments (reflecting a greater treatment by items variance compared with the treatment by subjects variance). The most likely interpretation of this result is that a limited number of subjects showed an orthographic effect at the slow speed, whereas the majority did not.

From the point of view of the contextual theory, the absence of a lexical or an orthographic effect for "same" items presents something of a problem. One possible line of argument is to propose that the task itself is not conducive to the demonstration of a context effect. For example, there is some evidence that introducing a delay between the two stimuli changes the nature of the processing (e.g., Marmurek, 1977; Swift, 1977). The delay means that the subject has already just processed the target item $2 \mathrm{sec}$ previously, and it is possible that a recency effect acts to minimize possible context effects.

The most obvious counter to this argument is to point out that this delay did not eliminate the familiarity effects at the fast presentation speed. To cope with this result, the contextual theory would have to invoke special assumptions about the effects of rapid serial presentation.

However, it must be conceded that the delay condition is not a critical feature of the experiment, since the race model derives its predictions from assumptions about the rate at which decisions at the letter level can be made. Hence the same results ought to be obtained when the delay is eliminated. The next experiment was designed to test this hypothesis.

\section{EXPERIMENT 2}

To remove the delay condition, but preserve the serial presentation, it is necessary to use synchronous serial presentation of both stimuli. That is, both stimuli are presented letter by letter at the same rate. Thus a typical display would develop in the following way:

$\begin{array}{lllll}\mathrm{C} & \mathrm{CH} & \text { CHA } & \text { CHAR } & \text { CHART } \\ \mathrm{C} & \mathrm{CH} & \text { CHA } & \text { CHAR } & \text { CHART }\end{array}$

\section{Method}

Design. The design of this experiment was identical in all respects to the previous experiment.

Procedure. The letters of both stimuli were incrementally displayed in synchrony at rates of either $40 \mathrm{msec} / \mathrm{letter}$ pair or $400 \mathrm{msec} / \mathrm{letter}$ pair. Subjects were again instructed to respond "different" as soon as any difference was detected and otherwise to respond "same" when the final pair of letters was presented. To enable the subject to determine when the display was complete, the positions in which the letters would be displayed was clearly marked beneath the display in the following way

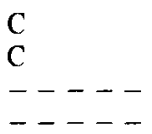

These markers were constant throughout the experiment. All other features of the procedure were the same as in the previous experiment. Timing of the response began as the last pair of letters was presented.

Subjects. A total of 30 volunteer graduates and undergraduates served as subjects and were paid for their participation.

\section{Results and Discussion}

The mean decision times for "same" items are shown in Table 2. Overall, responses were slower than in Experiment 1 , reflecting the absence of any priming action due to prior presentation of the first stimulus. Results of the 2 by 3 by 2 analysis of variance of these means showed the same three effects as Experiment 1. Responses were faster at the slow rate $\left[\min F^{\prime}(1,41)=52.6\right.$, $\mathrm{p}<.001]$. There was an overall main effect of item type

Table 2

Mean Decision Times (RT) in Milliseconds and Percent Error Rates (PE) for "Same" Items in a Synchronous Serial Presentation Matching Task (Experiment 2)

\begin{tabular}{lcccccccc}
\hline & \multicolumn{2}{c}{ Words } & & \multicolumn{3}{c}{ Legal Nonwords } & \multicolumn{2}{c}{ Illegal Nonwords } \\
\cline { 2 - 3 } $\begin{array}{l}\text { Presenta- } \\
\text { tion Rate }\end{array}$ & RT & PE & & RT & PE & & RT & PE \\
\hline Fast & 633 & 4.6 & & 714 & 8.0 & 791 & 12.0 \\
Slow & 571 & 4.0 & & 598 & 6.7 & & 599 & 8.0 \\
\hline
\end{tabular}


$\left[\min F^{\prime}(2,128)=14.33, \mathrm{p}<.001\right]$, but this factor interacted with the speed factor $\left[\min F^{\prime}(2,129)=11.27\right.$, $\mathrm{p}<.001]$. As in Experiment 1, the error rates followed the general pattern of decision times, but in this case, the only effect to reach significance was that of item type $\left[\min \mathrm{F}^{\prime}(1,135)=4.67, \mathrm{p}<.05\right]$.

Pairwise comparisons showed that at the fast speed, there was a significant lexical effect of $81 \mathrm{msec}$ [min $\left.F^{\prime}(1,81)=20.96, p<.001\right]$ and a significant orthographic effect of $77 \mathrm{msec}\left[\mathrm{min} \mathrm{F}^{\prime}(1,80)=12.78\right.$, $\mathrm{p}<.001]$. At the slow speed, however, neither effect was statistically reliable. The lexical effect of $27 \mathrm{msec}$ was not significant $\left[\min \mathrm{F}^{\prime}(1,53)=1.14, \mathrm{p}>.05\right.$ (neither $F_{1}$ nor $F_{2}$ was significant)], and the orthographic effect of $1 \mathrm{msec}$ was obviously also not significant $\left[\min \mathrm{F}^{\prime}<1\right]$.

Once again, although the slow presentation condition clearly produced a substantial reduction in the size of the familarity effects, it is not absolutely clear that these effects were totally eliminated, since the $27-\mathrm{msec}$ difference between words and legal nonwords is not markedly less than the 38-msec lexical effect observed for the fast condition in Experiment 1.

However, it would be difficult to interpret this effect as a context effect (overlooking the lack of significance), given the complete absence of any orthographic effect. Possibly, this trend reflects a special strategy adopted by some subjects (once again $F_{2}$ was larger than $F_{1}$ ). For example, some subjects may have correctly anticipated the final letter when the stimulus was a word, and this may have produced a facilitative effect. Thus, given SHOR-, there is one chance in two of guessing the final letter correctly, provided that the stimulus is a word. If it is not, the probability will be much lower, and this may explain why there was no facilitation produced by orthographic structure alone.

Of course, it could be suggested that this process of anticipation is exactly what is meant by a context effect. If this argument was accepted, then it would have to be explained why a faster rate of presentation enhanced the facilitation effect (one might expect the reverse), and also why the purely orthographic effect only appeared at the fast presentation speed. Clearly, these effects require the postulation of a quite different kind of process.

\section{GENERAL DISCUSSION}

The results of these experiments demonstrate that apparent context effects in a simultaneous matching task are largely eliminated when the letters of the second stimulus are successively displayed at a rate of $400 \mathrm{msec} /$ letter. This is consistent with the view that processing at the individual letter level is unaffected by prior context and that the apparent context effects are a result of more efficient matching procedures at higher levels of processing.
These results are in close agreement with a parallel set of results for sentence matching (Forster, Ratcliff, \& Murray, Note 1). In these experiments, the effect of the semantic context of a sentence on recognition of a target word was investigated by comparing matching times for semantically plausible sentences, such as "Colorful flowers brightened the hall," and semantically implausible sentences, such as "Colorful flowers brightened the brawl." A delayed matching task was used; when the words of the second sentence were presented simultaneously (analogous to the fast presentation condition), clear effects of plausibility for "same" responses were demonstrated. However, when the words of the second stimulus were successively presented at a rate of $400 \mathrm{msec} /$ word, the effects of plausibility were eliminated. Thus there is a clear parallel between the results for sequences of words and sequences of letters; apparent context effects in both cases are not observed when the sequences are presented serially at reasonably slow rates.

The sentence-matching results can be explained in terms of the multilevel race model by postulating a higher level of processing, namely, a sentential level. At this level, decisions are based on a comparison of the meanings of the two sentences. This level of processing is faster than the lexical level with rapid (simultaneous) presentation, since fewer decisions need to be made. Since semantic plausibility would obviously affect comprehension time, this variable will affect matching time. But with slow serial presentation, the lexical level (or even a lower level) can keep pace with the input, and if this level of processing is unaffected by the preceding sentence, no effect of context will be observed.

The conclusions derived from the experiments reported in this paper strictly apply only to the samedifferent paradigm. However, the results also bear indirectly on the interpretation of the apparent context effects observed in the Reicher (1969) and Wheeler (1970) situation. If context exerted an effect on letter identification in the Reicher task, then it should have exerted a consistent effect in the present experiments as well. This suggests that an alternative explanation of the Reicher effects must be found.

One line of resistance to this conclusion is to argue that slow serial presentation somehow prevents the normal context effect from operating. For example, it seems reasonable to suppose that the contextual effect might be time-dependent. This would be the case if the context activated the appropriate letter detectors for only a brief period of time. If the next letter is not presented within that period, no facilitation occurs, nor is there any way in which the context can be reinstated or refreshed. This explanation would obviously account for the results of the present experiments, but it would do so at the cost of making the letter context effect completely different from other kinds of context effects. For example, the effect on word recognition of a semantically related context word shows no sign of diminishing 
even with a stimulus onset asynchrony of $2,100 \mathrm{sec}$ (Neely, 1976). Thus, unless there are independent grounds for postulating that the effect of context on letter recognition should be a far more transient effect, this argument lacks any real explanatory power.

There is an alternative treatment of the results reported in this paper that may integrate these findings with the results from the Reicher type of task. Perception can be thought of as a mix of inferences based primarily on the sensory data ("bottom-up" processing) and inferences derived from conceptual knowledge ("topdown" processing). The relative contribution of these two kinds of processing may depend on the demands placed on the limited processing capacities of the perceiver. When demands are high, top-down processing becomes more important, and hence contextual influences should be maximal. But when demands are low, the perceiver may rely more on bottom-up processing, and hence context plays only a limited role in perception. Applied to the same-different task, this model would predict stronger context effects for either simultaneous or rapid serial presentation conditions, since these conditions would make the greatest demands on processing capacity. In the slow serial presentation condition, in which only one letter pair needs to be processed at a time, the entire processing capacity can be focused on each letter pair in turn, and hence there is no need to utilize context-dependent processes. In the Reicher task, in which the stimulus is presented only briefly and is followed by a mask, processing demands are once again high, and thus the contextual effects are more pronounced.

Such a theory goes dangerously close to merely being a summary of the experimental results, unless it can be explained why the context-dependent mechanisms are only invoked in high-demand situations. If these mechanisms are so helpful in high-demand situations, why should they be abandoned in low-demand situations?

Much the same question arises in the case of the multi-level race model. Why is the lexical level of processing not still the fastest method of matching with slow serial presentation of letter sequences? It seems that the only possible answer to this question is that recognizing a word is at least as complex a process as recognizing a letter, despite the apparent contradiction of the Reicher (1969) experiments. Hence there is no advantage to a lexical method of matching when only one letter pair needs to be compared to reach a decision.

Distinguishing between these theories will not be easy, since factors that favor lower levels of processing in the race model will also tend to decrease demands on processing. One promising possibility is manipulation of the length variable. The race model predicts that short words such as "am," "be," and "of" should show minimal lexical effects even in a simultaneous matching task, since only two letter pairs, or perhaps one lettercluster pair, need to be compared, hence reducing the possible advantage of lexical processing. While the relevant results are not available for word matching, there are results from a sentence-matching experiment (Forster, Note 2) that suggest that length is important. In this experiment, the advantage of sentential methods of matching over lexical methods was much smaller for two-word sentences than for five-word sentences. However, since shorter sequences are matched more quickly than longer sequences, it might be argued that these results are a consequence of lowering the demands on processing capacity.

Despite the difficulties of distinguishing between these theories at present, one should not lose sight of the fact that both theories make one important assumption. They assume that contextual processes are not inevitably involved in recognition. This implies that there must exist context-free recognition systems that, under ideal circumstances, prove to be the most efficient methods of identifying stimuli.

\section{REFERENCE NOTES}

1. Forster, K. I., Ratcliff, J., \& Murray, W. S. A distinction between lexical and sentence context effects. Unpublished paper, Department of Psychology, Monash University, March 1978.

2. Forster, K. I. Lexical and sentential context effects in word recognition. Paper presented at the Fifth Australian Experimental Psychology Conference, La Trobe University, May 1978.

\section{REFERENCES}

Barron, R. W., \& Pittenger, J. B. The effect of orthographic structure and lexical meaning on same-different judgments. Quarterly Journal of Experimental Psychology, 1974, 26, 566581.

Clark, H. H. The language-as-fixed-effect fallacy: A critique of language statistics in psychological research. Journal of Verbal Learning and Verbal Behavior, 1973, 12, 335-359.

Chambers, S. M., \& Forster, K. I. Evidence for lexical access in a simultaneous matching task. Memory \& Cognition, 1975, 3, 549-559.

Marmurfi, H. Processing letters in words at different levels. Memory \& Cognition, 1977, 5, 67-72.

NeELY, J. H. Semantic priming and retrieval from lexical memory: Evidence for facilitatory and inhibitory processes. Memory \& Cognition, 1976, 4, 648-654.

Reicher, G. M. Perceptual recognition as a function of meaningfulness of stimulus material. Journal of Experimental Psychology, 1969, 81, 275-280.

SwIFT, D. J. The effects of context, word frequency, and internal redundancy in reading and word perception. Unpublished doctoral dissertation, University of New Hampshire, 1977.

Tном pson, M. C., \& Massaro, D. W. Visual information and redundancy in reading. Journal of Experimental Psychology, $1973,98,49-54$

WheEler, D. D. Processes in word recognition. Cognitive Psychology, 1970, 1, 59-85.

(Received for publication July 2, 1979; revision accepted November 26,1979 .) 